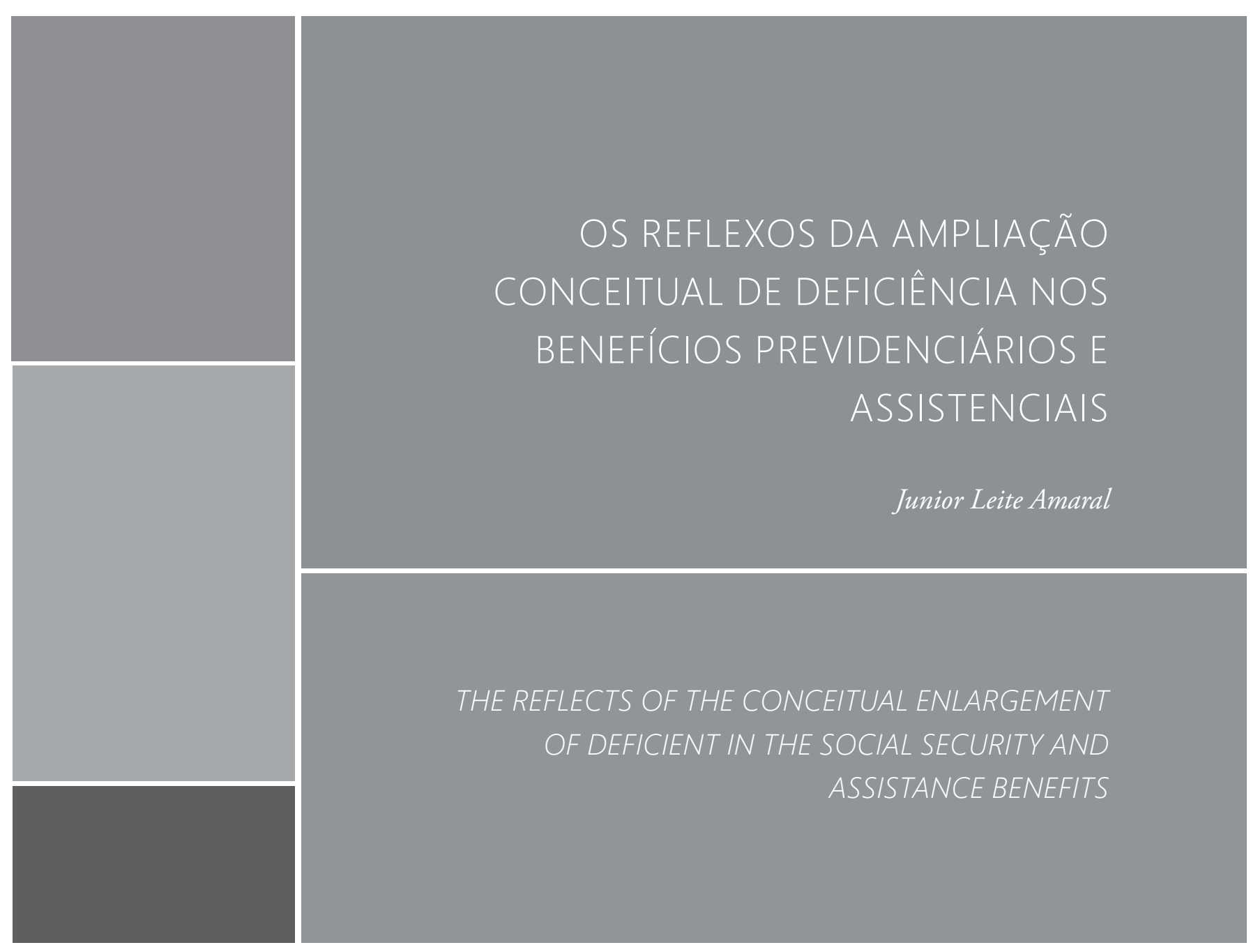




\section{OS REFLEXOS DA AMPLIAÇÁO CONCEITUAL DE DEFICIÊNCIA NOS BENEFÍCIOS PREVIDENCIÁRIOS E ASSISTENCIAIS}

THE REFLECTS OF THE CONCEITUAL ENLARGEMENT OF DEFICIENT IN THE SOCIAL

SECURITY AND ASSISTANCE BENEFITS.

Junior Leite Amaral Defensor Público Federal em Pelotas.

Especialista em Processo Civil pela Universidade de Caxias do Sul. Rio Grande do Sul, Brasil. junior.amaral@dpu.gov.br

\section{RESUMO}

Este artigo objetiva analisar as alteraçôes, bem como as implicações decorrentes da adoção, pelo Estado Brasileiro, da Convenção sobre os Direitos das Pessoas com Deficiência, incorporada formal e materialmente ao ordenamento constitucional, observando a ritualística estabelecida no $\$ 3^{\circ}$, do artigo $5^{\circ}$, da Constituição Federal de 1988. Para tanto, a abordagem ao tema dar-se-á sob o viés histórico, dialético e comparativo, sem prejuízo de pontuar e defender que o conceito de pessoa com deficiência deve desatrelar-se da concepção atinente a incapacidade revelada basicamente sob o aspecto físico/clínico, que para fração do entendimento judicial hodierno é aferível somente por profissional com formação em Medicina. Ao cabo, em razão dos reflexos decorrentes da ampliação semântica do conceito de deficiência, será proposta uma nova abordagem da incapacidade.

Palavras-chave: Conceito. Deficiente. Incapacidade. Reflexos. 


\begin{abstract}
This article aims to analyze the alterations, like the going implications of the adoption for the Brazilian State, of Convention about the Deficient Human Due, incorporated formal and material to the constitutional orderly, observing the ritualistic established in $\$ 3^{\circ}$, of the article 5 , from the Federal Constitution of 1988 . So that, the approach to the theme will be given under historical bias, dialect and comparative, without impairment of punctuate and defends what the concept of Deficient person should uncoupling of the regard conception of inability basically revealed under physio / clinical aspect of the hordienal judicial understanting fraction is gaugeable just for a professional with formation in Medicine. At the end, because of the reflections going of the semanticts enlargement of the concept of deficient, will be propose a new inability accost.
\end{abstract}

Keywords: Concept. Deficient. Inability. Reflections.

Data de submissão: 07/01/2016

Data de aceitação: 22/08/2017

\title{
SUMÁRIO
}

INTRODUÇÃO 1. A CONSTRUÇÃO DA PROTEÇÃO INTERNACIONAL ÀS PESSOAS COM DEFICIÊNCIA 2. A CONSTITUCIONALIZAÇÃO PELO ESTADO BRASILEIRO DOS DIREITOS DAS PESSOAS COM DEFICIÊNCIA 3. CONCEITO DE PESSOA COM DEFICIÊNCIA SEGUNDO A CONVENÇÃO DA ONU E AS IMPLICAÇÓES NA LEGISLAÇÃO BRASILEIRA 4. OS REFLEXOS DA AMPLIAÇÃO CONCEITUAL DE DEFICIÊNCIA NOS BENEFÍCIOS PREVIDENCIÁRIOS E ASSISTENCIAIS. CONSIDERAÇÓES FINAIS. 


\section{INTRODUÇÁO}

O estudo sobre a deficiência na atualidade, ao contrário do que se pode cogitar, não é um tema já esgotado ou sem maior relevância na seara jurídica. A importância do tema decorre, dentre outros motivos, do grande contingente de pessoas que possuem alguma deficiência, ao que a compreensão do profissional jurídico neste aspecto tende a permitir uma melhor instrução, resguardo e tutela das garantias estabelecidas a este segmento social, por longos períodos da história discriminados e que atualmente são considerados a maior minoria do mundo ${ }^{1}$, segundo a Organização das Naçóes Unidas (ONU). Neste aspecto, salutar são os dados mundiais divulgados pela $\mathrm{ONU}^{2}$, em passado recente, indicando que cerca de dez por cento da população mundial, aproximadamente 650 milhôes de pessoas, vivem com uma deficiência. A apuraçáo nacional, não difere muito da constatação mundial, já que segundo levantamento realizado pelo Instituto Brasileiro de Geografia e Estatística (IBGE), em parceria com o Ministério da Saúde, cerca de 6,2\% da população brasileira tem algum tipo de deficiência.

A evolução da ciência médica não significa(rá) o decréscimo do número de deficientes, até pelo fato de que a origem de algum impedimento não está atrelado a aspectos congênitos, hereditários, mas também e, inclusive, advém da própria relação entre as pessoas e dos percalços decorrentes destas. Ao tempo que o convívio em sociedade permite ajustes e colaboraçóes recíprocas em prol de um mundo melhor, inevitavelmente o agrupamento gera infortúnios indesejados a resultar na ocorrência de alguma deficiência a alguém, como exemplo pode-se citar os acidentes de qualquer natureza, os atos de violência de toda espécie, a submissão a agentes nocivos na atividade laboral, o efeito colateral de um tratamento médico, as sequelas geradas por doenças, entre muitas outras. Assentado o motivo do estudo, a presente exposição almeja analisar, sem esgotar o tema, registre-se, as consequências advindas com a absorção do conceito de deficiência na ordem jurídica constitucional, sob o status formal e material, instigando o debate sobre a necessidade de reavaliação da forma como a constatação da deficiência é realizada no âmbito administrativo e judicial, quando da análise de um benefício previdenciário ou assistencial. Para tanto, far-se-á uma análise histórica das proteçôes conferidas às pessoas com deficiência e, na sequência, a mutação conceitual de deficiência, conquanto a supressão destas etapas não

1 A ONU e as pessoas com deficiência. Disponível em: <https://nacoesunidas.org/acao/pessoascom-deficiencia/> Acesso em: 01 de jul. 2016.

2 INSTITURO 6,2\% da população têm algum tipo de deficiência. Disponível: http://www.ebc. com.br/noticias/2015/08/ibge-62-da-populacao-tem-algum-tipo-de-deficiencia Acesso em: 01 de jul. 2016. 
permitiria ao leitor o entendimento da extensão do debate proposto que, por fim, visa buscar, o aperfeiçoamento do método para aferir a deficiência e o grau de sua intensidade.

\section{A CONSTRUÇÃO DA PROTEÇÃO INTERNACIONAL ÀS PESSOAS COM DEFICIÊNCIA}

No percurso da história da humanidade foram outorgados inúmeros tratamentos às pessoas com deficiência, e neste aspecto, quatro foram os estágios de evolução, ou melhor, de construção ${ }^{3}$ dos direitos das pessoas com deficiência, consoante Flávia Piovesan ${ }^{4}$,

Com efeito, a história da construçáo dos direitos humanos das pesso-
as com deficiềncia demarca quatro fases: a) uma fase de intolerância
em relaçấo às pessoas com deficiência, em que a deficiência simbo-
lizava impureza, pecado ou mesmo castigo divino; b) uma fase mar-
cada pela invisibilidade das pessoas com deficiência; c) uma terceira
fase orientada por uma ótica assistencialista, pautada na perspectiva
médica e biológica de que a deficiência era uma "doença a ser cura-
da", sendo o foco centrado do indivíduo "portador da enfermidade; e
d) finalmente uma quarta fase orientada pelo paradigma dos direitos
humanos, em que emergem os direitos à inclusão social, com ênfase
na relação da pessoa com deficiência e do meio em que ela se insere (...)

A partir das fases retrocitadas, conjugada com a adoção de medidas internacionais voltadas à proteção do indivíduo em si considerado, este inserido num processo denominado especificação do sujeito de direitos, que para Noberto Bobbio 5 "o próprio homem não é mais considerado como ente genérico, ou homem abstrato, mas é visto na especificidade ou na concreticidade de suas maneiras de ser em sociedade, como criança, velho, doente, etc", promoveu-se a tutela dos deficientes. A premissa alhures construída (proteção individuo em si) não é fundada no método dedutivo, mas sim, decorre de uma constatação histórica a partir das convençôes internacionais editadas pela Organização das Naçôes Unidas desde o surgimento do Direito Internacional dos Direitos Humanos.

\footnotetext{
3 A adoção do vernáculo construção em substituição à palavra evoluçáo decorre pelo fato de que os estágios históricos citados no texto náo podem ser considerados, em especial entre a primeira e a terceira etapa, como evolutivos.

$4 \quad$ PIOVESAN, F. Temas de Direitos Humanos. Saraiva: São Paulo, 2009, pg. 303.

5 BOBBIO, N. A era dos Direitos, 1992. In: PIOVESAN, F. Temas de Direitos Humanos. Saraiva: São Paulo, 2009, p. 300.
} 
Como de sabença geral, o motivo indutor a construção de uma proteção internacional aos Direitos Humanos foram as atrocidades cometidas ao longo da Segunda Guerra Mundial, instante histórico em que existiu a segregação, o extermínio e inúmeros outros atentados a pessoas ou a grupos determinados de indivíduos que não se enquadravam no perfil eleito como adequado pelos opressores. Nesse sentido, Flávia Piovesan ${ }^{6}$ acentua,

O 'Direito Internacional dos Direitos Humanos' surge, assim, em meados do século XX, em decorrência da Segunda Guerra Mundial, e seu desenvolvimento pode ser atribuído às monstruosas violaçôes de direitos humanos da era Hitler e à crença de que parte dessas violaçóes poderia ser prevenida, se um efetivo sistema de proteção internacional de direitos humanos existisse.

Nasce, portanto, da Segunda Guerra Mundial a necessidade de proteção internacional dos direitos humanos, e como primeira exteriorizaçáo internacional do consenso sobre a necessidade de ampliação de garantias para além da jurisdição doméstica de Estados soberanos, em 1948, edita-se a Declaração Universal dos Direitos Humanos.

Em consequência deste movimento, inúmeras outras convenções internacionais foram acordadas, tendo como norte a proteção do indivíduo em si e por seus critérios de diferenciação, estes fundados no sexo, idade, condição física, tudo para garantir um tratamento especializado. Como exemplos, desta nova fase de guarida, são as Convençôes sobre os Direitos do Deficiente Mental, Convenção 159/83 da OIT, sobre os Direitos da Criança, de Eliminação de Todas as Formas de Discriminação Racial, entre outras.

Insere-se, portanto, neste fluxo internacional de resguardo a Convenção Sobre os Direitos das Pessoas com Deficiência.

\section{A CONSTITUCIONALIZAÇÃO PELO ESTADO BRASILEIRO DOS DIREITOS DAS PESSOAS COM DEFICIÊNCIA}

Em 25 de agosto de 2009, quando da promulgação do Decreto n 6.949/2009, eclodiuse uma nova era no direito constitucional interno sobre a proteção das pessoas com deficiência. A promulgação do referido decreto, observando a ritualística procedimental legislativa estabelecida no $\$ 3^{\circ}$, do artigo $5^{\circ}$, da Magna Carta, consistiu num passo importante para ampliar a salvaguarda da proteção ao exercício pleno e efetivo de todos os direitos e liberdades fundamentais das pessoas com deficiência.

6 PIOVESAN, F. Temas de Direitos Humanos. Saraiva: São Paulo, 2009, p. 04. 
O status constitucional do Decreto, tanto no sentido formal, quanto material, foi a primeira manifestação político-legislativa brasileira, após a Emenda Constitucional 45/04, no sentido de estabelecer força normativa constitucional a Tratado Internacional sobre Direitos Humanos. Com relevo, a incorporação da Convençáo internacional sobre os Direitos das Pessoas com Deficiência na ordem jurídica constitucional brasileira, tal como delineado na ratio decidendi pelo Supremo Tribunal Federal, na ocasiáo do julgamento do RE 349.703/RS, constitui referência ao restrito ${ }^{7}$ bloco de constitucionalidade brasileiro.

A incorporação constitucional dos conceitos e regramentos da Convenção importam sérias consequências à legislação infraconstitucional interna, em especial em relação àquelas contrárias aos preceitos versados no documento internacional. Nessa toada, a superveniência de norma constitucional em contradição a direito ordinário infraconstitucional importa na "derrogação do direito anterior com ela incompatível ${ }^{8 ”}$.

Tendo como norte os reflexos decorrentes da superveniência de norma constitucional contraposta a direito infraconstitucional anterior àquela, quando promulgado o Decreto 6.949/2009, o conceito de deficiência preconizado pelo direito infraconstitucional restou derrogado, assunto que será amplamente abordado no próximo tópico.

\section{CONCEITO DE PESSOA COM DEFICIÊNCIA SEGUNDO A CON- VENÇÃO DA ONU E AS IMPLICAÇÓES NA LEGISLAÇÁO BRASILEIRA}

A construçáo do conceito de deficiência no campo do direito interno, sem sombra de dúvidas, sofreu influência da área da saúde, porquanto até o ano de 2001, conforme Classificaçấo Internacional de Deficiências incapacidades e desvantagens, publicada em 1976, a deficiência era tida como':

\footnotetext{
O vernáculo a que se refere esta nota foi inserido propositalmente pelo autor, eis que a partir da decisão do STF acerca dos status das normas de direito internacional quando da sua incorporação ao direito interno restou estabelecido um retrocesso no que tange a amplitude do bloco de constitucionalidade brasileiro. Ora, enquanto grande segmento da doutrina especializada acerca do tema, como, por exemplo, Flávia Piovesan, defendia que o bloco de constitucionalidade brasileiro fosse considerado amplo, com fundamento na cláusula de abertura do artigo $5^{\circ}, \$ 2^{\circ}$ da Constituiçáo, prevaleceu no STF o posicionamento do Ministro Gilmar Mendes, ao estabelecer equivalência constitucional, supralegal ou de lei ordinária, a depender do tema e do rito procedimental legislativo adotado pelo Poder Legiferante.

8 MENDES, G. F. Curso de Direito Constitucional. 6. ed., Saraiva: São Paulo, 2011, p. 1075.

9 Almiralian, M. L. T. et. al. Conceituando Deficiência. In: MATHEUS, N. de M.; SCHLIEMANN, A. L. A construçáo do conceito de deficiência na área da saúde. Disponível em: http:// www4.pucsp.br/pac/downloads/artigo_construcao_conceito.pdf. Acesso em: 12 nov. 2015.
} 
perda ou anormalidade de estrutura ou função psicológica, fisiológica ou anatômica, temporária ou permanente. Incluem-se nessas a ocorrência de uma anomalia, defeito ou perda de um membro, órgão, tecido ou qualquer outra estrutura do corpo, inclusive das funçóes mentais. Representa a exteriorização de um estado patológico, refletindo um distúrbio orgânico, uma perturbação no órgáo.

$\mathrm{O}$ aspecto clínico da deficiência era táo preponderante na sociedade como um todo, que a redação original da Lei Orgânica da Assistência Social (Lei 8.742/93) estabelecia a pessoa com deficiência como incapaz:

\section{Art. 20. [...]}

$\$ 2^{\circ}$ Para efeitos de concessão deste benefício, a pessoa portadora de deficiência é aquela incapacitada para a vida independente e para o trabalho.

As críticas, na área da saúde, quanto no campo do direito, caminhavam no mesmo sentido, posto que a deficiência não deveria se resumir estritamente ao aspecto físico, vejamos:

[...] não são apenas uma conseqüência das condiçóes de saúde/doença, mas são determinadas também pelo contexto do meio ambiente físico e social, pelas diferentes culturais e atitudes em relação à deficiência, pela disponibilidade de serviços e de legislação. ${ }^{10}[\ldots]$ Fez muito mal, pois definiu pessoa com deficiência, para efeito deste benefício, como aquela incapacitada para a vida independente e para o trabalho (art. $20, \$ 2^{\circ}$ ). Tal definição choca-se, frontalmente, com todo o movimento mundial pela inclusão da pessoa com deficiência. Num momento em que se procura ressaltar os potenciais e as capacidades da pessoa com deficiência, por esta lei, ela deve demonstrar exatamente o contrário. [...] Muitos pais acabam impedindo seus filhos com deficiência de estudar e de se qualificar, justamente para não perderem o direito a esse salário mínimo. ${ }^{11}$

Não é por menos que a adoção pelo Estado Brasileiro, ainda que tardia, da conceituação de deficiência estabelecida pela Convenção da ONU foi festejada pela doutrina, motivo propulsor, registre-se, da impetração pelo Procurador Geral da República da ADPF nº

10 FARIAS, N. \& BUCHALLA, C. M. A Classificação Internacional de Funcionalidade, Incapacidade e Saúde da Organização Mundial da Saúde: Conceitos, Usos e Perspectivas. In: ALMIRALIAN, M. L. T. et. al. Conceituando Deficiência. In: MATHEUS, N. de M.; SCHLIEMANN, A. L. A construçáo do conceito de deficiência na área da saúde. Disponível em: http://www4.pucsp.br/pac/downloads/artigo_ construcao_conceito.pdf. Acesso em: 12 nov. 2015.

11 FÁVERO, E. A. G. Direitos das pessoas com deficiência: garantia de igualdade na diversidade. In: TSUTSUI, P. F. O novo conceito de pessoa com deficiência. Conteudo Juridico, Brasilia-DF: 18 mar. 2014. Disponivel em: <http://www.conteudojuridico.com.br/?artigos\&ver=2.47458\&seo=1>. Acesso em: 15 nov. 2015. 
$182^{12}$, perante o Supremo Tribunal Federal, isto para que fosse reconhecido derrogado o conceito de deficiência alicerçado no artigo $20, \$ 2^{\circ}$, da Lei 8.743/93.

Com destaque, segundo preâmbulo do documento internacional, a deficiência é um conceito em evolução ao que impóe, por conta das diversas formas de deficiência, tratamento especializado às pessoas com deficiência, observando o grau de necessidade de cada um, nos termos das alíneas "e" e “j”:

Reconhecendo que a deficiência é um conceito em evolução e que a deficiência resulta da interaçáo entre pessoas com deficiência e as barreiras devidas às atitudes e ao ambiente que impedem a plena e efetiva participaçáo dessas pessoas na sociedade em igualdade de oportunidades com as demais pessoas, reconhecendo ainda a diversidade das pessoas com deficiência,

A partir dos preâmbulos retrocitados, tem-se que a definição de pessoa com deficiência não poderia ser diversa da que estampada no artigo $1^{\circ}$, da Convenção,

Pessoas com deficiência são aquelas que têm impedimentos de longo prazode naturezafísica, mental, intelectual ou sensorial, os quais, eminteração com diversas barreiras, podem obstruir sua participação plena e efetiva na sociedade em igualdades de condiçôes com as demais pessoas.

Além de superar fatores meramente biológicos, a conceituação prioriza uma dimensão social, posto que "deverâo ser consideradas a sociedade e a cultura em que a pessoa está inserida. ${ }^{13 "}$. Segundo Ricardo Tadeu Marques da Fonseca ${ }^{14}$ :

O conceito de pessoa com deficiência adotado pela Convenção supera as legislaçôes tradicionais que normalmente enfocavam o aspecto clínico da deficiência. As limitaçôes físicas, mentais, intelectuais ou

\footnotetext{
12 A argüição de descumprimento de preceito fundamental, segundo tramitação processual ofertada em consulta pública no site do STF, está conclusa com o Relator desde o ano de 2009, ainda pendente de apreciação, mas sem sombra de dúvidas, por conta das alterações supervenientes da legislação ordinária, perdeu efeito a ação.

13 ARAUJO, E. A. B. S.; FERRAZ, F. B. O conceito de pessoa com deficiência e seu impacto nas açóes afirmativas no mercado de trabalho. Trabalho apresentado no XIX Encontro Nacional do CONPEDI, Fortaleza, 2010. Disponível em: http://www.repositorio.ufc.br/bitstream/riufc/541/1/2010_ eve_fbferraz.pdf. Acesso em: 12 nov. 2015.

14 FONSECA, R. T. M. A ONU e o seu Conceito Revolucionário de Pessoa com Deficiência. Disponível em: http://www2.portoalegre.rs.gov.br/smacis/default.php?reg=4\&p_secao=96. Acesso em: 12 nov. 2015.
} 


\begin{abstract}
sensoriais passam a ser consideradas atributos das pessoas, atributos esses que podem ou não gerar restriçóes para o exercício dos direitos, dependendo das barreiras sociais ou culturais que se imponham aos cidadãos com tais limitaçóes, o que possibilita afirmar-se que a deficiência é a combinação de limitaçôes pessoais com impedimentos culturais, econômicos e sociais. Desloca-se a questáo do âmbito do individuo com deficiência para as sociedades que passam a assumir a deficiência como problema de todos.
\end{abstract}

No âmbito da legislação infraconstitucional, em 2011, ocorreram duas mudanças no conceito de pessoa com deficiência, a primeira em julho daquele ano em decorrência da Lei 12.435 e, a segunda, em agosto, ou seja, menos de um mês após a primeira alteração. No primeiro enunciado legal o legislador ordinário muito se aproximou do conceito constitucional, olvidando de descrever o impedimento de natureza mental e, por fim, a locução "em igualdade de condiçôes". Superados os vícios, desde 2011, vige no regime jurídico brasileiro o conceito de deficiência trazido pela Convenção.

É verdade que, por conta da vacatio legis de 180 (cento e oitenta) dias, somente no ano de 2016, o Estatuto da Pessoa com Deficiência (Lei 13.146/2015) terá vigência e, com isto, restará, novamente, em menos de 5 (cinco) anos, alterado o conceito de pessoa com deficiência. Semântica e juridicamente a alteração promovida não trará implicaçôes negativas a proteção das pessoas com deficiência, porém sob o ponto positivo, o raciocínio não é o mesmo. Para melhor compreensão, pedimos vênia para transcrever o disposto no artigo 105, da Lei 13.146/2015:

$\S 2^{\circ}$ Para efeito de concessão do benefício de prestação continuada, considera-se pessoa com deficiência aquela que tem impedimento de longo prazo de natureza física, mental, intelectual ou sensorial, o qual, em interaçáo com uma ou mais barreiras, pode obstruir sua participaçáo plena e efetiva na sociedade em igualdade de condiçóes com as demais pessoas.

Da nova redação atribuída ao conceito de deficiência constata-se a opção por tornar dispensável a multiplicidade de impedimentos e de barreiras à caracterização. Por conseguinte, ainda que sensível a alteração conceitual, tem-se que tal constituiu uma reafirmação à proteçấo dos direitos das pessoas com deficiência, sem qualquer ocorrência de vício de inconstitucionalidade, bem como não houve qualquer retrocesso à proteção das pessoas com deficiência, como encadeamento do princípio da vedação ao retrocesso social contido no artigo $4^{\circ}$, da Convenção da ONU. Aliás, a alteração, em verdade, objetiva descomplexificar o reconhecimento da condição de deficiente, conquanto um 
único impedimento em interação com uma barreira já é suficiente, por reflexo, a proteção assistencial.

\section{OS REFLEXOS DA AMPLIAÇÁO CONCEITUAL DE DEFICIÊNCIA NOS BENEFÍCIOS PREVIDENCIÁRIOS E ASSISTENCIAIS}

Indiscutível é a repercussão positiva decorrente da ampliação conceitual de deficiência nos direitos sociais, em especial os da seguridade social. Propositalmente, alocou-se a seguridade social em destaque, porquanto uma vez reconhecida que a deficiência não se cinge a critérios biológicos, mas sim, também e, inclusive, a outros impedimentos como os de natureza mental, sensorial, intelectual, que em interação com qualquer entrave/ barreira limita a plena participação social da pessoa, tal aspecto resultará na adoção de proteção especializada na proteção do direito à saúde, além do direito à previdência e/ou seguridade social dos deficientes.

Por tal aspecto, sem desconhecer a existência de entendimento advogando sentido inverso ${ }^{15}$, tem-se que a alteração conceitual promovida pela acolhida na ordem jurídica interna da Convenção da ONU sobre direito das pessoas com deficiência não poderá, nem muito menos este é o mote do Protocolo Internacional, promover a exclusão de quem era/foi considerado deficiente, nos moldes do aspecto biológico/fisiológico.

Com relevo, ao estabelecer no preâmbulo da Convenção que toda pessoa faz jus a todos os direitos e liberdades, sem distinção de qualquer espécie, bem como a necessidade de se

15 Segundo Maurício Maia em Novo conceito de pessoa com deficiência e proibiçáao do retrocesso, não é difícil imaginar a situação em que alguém, por conta do conceito preconizado pela Convenção da ONU, promulgada pelo Decreto 6.949/2009, deixe de ser considerado pessoa com deficiência, notadamente quando a constatação a tal impedimento decorreu exclusivamente sob o aspecto de uma situaçáo fisiológica e médica. Mais além, o mesmo articulista defende que não haveria retrocesso social ao excluir àqueles do âmbito de proteçáo da assistência social quando apurado que o impedimento fisiológico não obstrua plenamente a participação social. De nossa parte, é certo que apuração do impedimento não se circunscreve, atualmente, ao aspecto médico, mas sim o social, ao que existindo um entrave/barreira, seja urbanístico, arquitetônico, nos transportes, nas comunicações e na informação, atitudinais, tecnológicos, entre outros, não haverá igualdade de condiçóes para permitir a participaçáo plena e efetiva em sociedade do deficiente. Na sociedade brasileira, apesar da existência de inúmeras normas garantindo a acessibilidade a espaços públicos, repartiçóes públicas, é comum, por incrível que parece, a inadequação destes àqueles com algum impedimento. Com destaque, sequer rapas de acesso às calçadas estão dispostas à plena disposição, o que se dirá então, o acesso à transportes, às comunicaçóes, às informaçôes. Por tudo isso, enquanto não houver a correção do meio social, com a efetivaçáo de todos instrumentos aptos a franquear a possibilidade de participaçáo independente em sociedade, pode-se concluir que não haverá igualdade de condiçôes entre os deficientes e os que nâo o são. 
garantir que todas as pessoas com deficiência os exerçam plenamente sem discriminação, restou subentendido que não é prescindível a busca pela igualdade material. E para se alcançar a igualdade sob o aspecto material, consoante liçâo da doutrinadora paulista Flávia Piovesan, se faz necessária a implementação de políticas afirmativas combinadas com incentivos ao fim da discriminação. Para ela ${ }^{16}$ :

[...] a igualdade e a discriminação pairam sob o binômio inclusão-exclusão. Enquanto a igualdade pressupóe formas de inclusão social, a discriminação implica a violenta exclusão e intolerância à diferença e diversidade. [...] Nesse sentido, como poderoso instrumento social, situam-se as açôes afirmativas. Essas açōes constituem medidas especiais e temporais que, buscando remediar um passado discriminatório, objetivam acelerar o processo de igualdade, com o alcance da igualdade substantiva por parte de grupos vulneráveis, como as minorias étnicas e raciais, as mulheres, dentre outros grupos.

Assim, a utilização de açóes afirmativas tem o escopo de fortalecer a busca constitucional pela igualdade material, isto para refutar discriminaçóes históricas e para que a todos sejam dadas as mesmas possibilidades - isto além do viés formal.

No campo do direito previdenciário e assistencial, o reconhecimento da existência do impedimento, desde que atendidos outros requisitos de elegibilidade estabelecidos nas legislaçốes pertinentes, que não serão objeto de estudo deste trabalho para evitar a fuga ao tema proposto para análise, poderá implicar no reconhecimento a uma prestação estatal.

Especificamente na seara previdenciária, o conceito importado da Convençáo da ONU estabelece a necessidade de apuração da inaptidão laboral do deficiente náo lastreada basicamente a critérios fisiológicos/clínicos, mas sob o prisma social, à semelhança do que é estabelecido ao portador do vírus $\mathrm{HIV}^{17}$. Em verdade, o enunciado sumular n ${ }^{\circ} 77$ da TNU, que franqueia a possibilidade do julgador não analisar as condiçốes pessoais e sociais quando não reconhecida a incapacidade laboral para a atividade habitual, no nosso sentir, caminha na contramão dos objetivos descritos pela Convenção da ONU no artigo $1^{\circ}$. Ora, se para ser considerado deficiente é imprescindível a análise social em que inserida aquela pessoa, notadamente com vistas a apurar a existência de uma ou mais barreiras, como então é possível desconsiderar o meio social se apenas por critérios

16 PIOVESAN, F. Temas de Direitos Humanos, 2009, p. 189.

17 Estabelece o enunciado sumular $n^{\circ} 78$ da TNU: "Comprovado que o requerente de benefício é portador do vírus HIV, cabe ao julgador verificar as condiçóes pessoais, sociais, econômicas e culturais, de forma a analisar a incapacidade em sentido amplo, em face da elevada estigmatização social da doença.” 
clínicos restou assentado que há aptidão laboral. Não se pretende com este pensamento vincular, como o era feito anteriormente pela legislação, a deficiência à concepção de incapacidade. Todavia, a incapacidade do deficiente decorre além do aspecto físico/ clínico, por consequência, o indeferimento de prestação beneficiária ao deficiente calcada na interpretação sufragada pela TNU na súmula supracitada importa em violação a preceito fundamental constitucional, recordando que a Convenção é norma inserida no bloco de constitucionalidade.

Aqui está, portanto, uma meta a ser perseguida por aqueles que advogam em prol dos deficientes na tutela da proteçấo assistencial ou previdenciária, missão consentânea a função institucional da Defensoria Pública da União, qual seja, a fomentar a discussão sobre a necessidade de revisão, à luz do Decreto 6.949/2009 e da Lei 13.146/2015, da prática adotada na fase instrutória para apuração da inaptidão ou impedimento de longo prazo. Como defendido ao longo deste trabalho a análise das condições sociais ao encargo de profissional especializado ou, até mesmo, de equipe multidisciplinar, esta formada por médicos, psicólogos, assistentes sociais e outros profissionais da saúde, merece análoga relevância, no julgamento da (in)existência de um impedimento a justificar a salvaguarda estatal. Sem desconhecer a recente inclinação jurisprudencial nesse sentido, perceptível da leitura da súmula da TNU no $80^{18}$, análogo pensamento deve ser incorporado à seara previdenciária, onde ainda prevalece o aspecto clínico/físico da inaptidão.

No âmbito legislativo já se vislumbra uma inclinação para acolhimento da tese acima exposta, neste particular destaca-se o Estatuto da Deficiência, editado com base na Convenção sobre os Direitos das Pessoas com Deficiência, que prevê expressamente a possibilidade da avaliaçấo da deficiência, quando necessário, ser biopsicossocial ao encargo de equipe multiprofissional e interdisciplinar ${ }^{19}$. A despeito da crítica quanto ao termo 'quando necessário' estabelecido no $\$ 1^{\circ}$, do artigo $2^{\circ}$ da Lei $13.146 / 2015$, em nosso sentir, a possibilidade de avaliação multiprofissional e interdisciplinar é reflexo da incorporação constitucional do conceito de deficiência.

\footnotetext{
18 Nos pedidos de benefício de prestação continuada (LOAS), tendo em vista o advento da Lei 12.470/11, para adequada valoração dos fatores ambientais, sociais, econômicos e pessoais que impactam na participação da pessoa com deficiência na sociedade, é necessária a realização de avaliação social por assistente social ou outras providências aptas a revelar a efetiva condição vivida no meio social pelo requerente.

19 Sobre o tema vide $\$ 1^{\circ}$, do artigo $2^{\circ}$, da Lei 13.146/2015: $₫ 1^{\circ}$ - A avaliação da deficiência, quando necessária, será biopsicossocial, realizada por equipe multiprofissional e interdisciplinar e considerará: I - os impedimentos nas funçóes e nas estruturas do corpo; II - os fatores socioambientais, psicológicos e pessoais; III - a limitação no desempenho de atividades; e IV - a restrição de participação.
} 
Diante disso, como efeito da Convenção sobre a legislação interna, o julgador não pode se furtar de examinar o aspecto social em sentido lato, quando do julgamento de causa previdenciária e assistencial.

\section{CONSIDERAÇÓES FINAIS}

A constitucionalização do conceito de deficiência importa na impossibilidade de aboliçẫo dos direitos e garantias individuais estabelecidas a este segmento, assim como traz consequências na interpretação das normas infraconstitucionais editadas anterior ou supervenientemente à Convenção sobre Direitos das Pessoas com deficiência, tanto em relação ao direito à saúde, como à previdência e à assistência social. A primeira consequência da importaçáo constitucional do conceito é a derrogação da lei infraconstitucional incompatível e o reconhecimento da inconstitucionalidade da legislaçáo conflitante editada posteriormente.

No plano do direito previdenciário e assistencial, a constitucionalização extirpou qualquer inclinação no sentido de atrelar a deficiência à incapacidade. Destacando-se, inclusive, que a incapacidade social do deficiente, concomitante ou alternativamente à inaptidão clínica/física, constitui justa causa ao deferimento de proteção pelo Estado. Nesta medida, as condiçóes pessoais do deficiente, bem como o contexto social em que ele está inserido, adquirem contornos típicos de requisitos de elegibilidade não expressos, nitidamente de suporte constitucional, que devem ser interpretados de modo favorável ao portador de algum impedimento. Diante disso, é inaceitável, quer administrativa, quando judicialmente, a análise solitária e não conjugada do impedimento de longo prazo e das barreiras, especialmente às de contorno social.

Assim, qualquer interpretação ou enunciado legal que constitua óbice a análise do meio social em que inserido o individuo e a existência de barreiras a ponto de acarretar sua inaptidáo para atividade habitual, configura violaçáo à Constituiçáo Federal. Portanto, a prova social, ao encargo de equipe multidisciplinar e interdisciplinar, deve, no entender do articulista, ser reclamada preponderantemente à prova técnica realizada basicamente sob o aspecto clínico/físico, porquanto a primeira melhor retratará a existência de barreiras sociais, atitudinais, arquitetônicas, tecnológicas e outras que inviabilizam a plena e efetiva participação do deficiente na sociedade. 


\section{REFERÊNCIAS}

ARAUJO, E. A. B. S.; FERRAZ, F. B. O conceito de pessoa com deficiência e seu impacto nas açóes afirmativas no mercado de trabalho. Trabalho apresentado no XIX Encontro Nacional do CONPEDI, Fortaleza, 2010. Disponível em: http://www. repositorio.ufc.br/bitstream/riufc/541/1/2010_eve_fbferraz.pdf. Acesso em: 12 nov. 2015 .

ALMIRALIAN, M. L. T. et. al. Conceituando Deficiência. In: MATHEUS, Natália de Mesquita; SCHLIEMANN, A. L. A construçáo do conceito de deficiência na área da saúde. Disponível em: http://www4.pucsp.br/pac/downloads/artigo_construcao_ conceito.pdf. Acesso em: 12 nov. 2015.

BRASIL. Constituição da República Federativa do Brasil. Brasília: Senado Federal, 1988.

. Decreto 6.949, de 25 de agosto de 2009. Promulga a Convençáo Internacional sobre os Direitos das Pessoas com Deficiência e seu Protocolo Facultativo, assinados em Nova York, em 30 de março de 2007. Diário Oficial [da] República Federativa do Brasil, Brasília, DF.

Lei 13.146, de 6 de julho de 2015. Institui a Lei Brasileira de Inclusáo da Pessoa com Deficiência (Estatuto da Pessoa com Deficiência). Diário Oficial [da] República Federativa do Brasil, Brasília, DF.

Lei 8.742 , de 7 de dezembro de 1993. Dispóe sobre a organizaçáo da Assistência Social e dá outras providências. Diário Oficial [da] República Federativa do Brasil, Brasília, DF.

FARIAS, N. \& BUCHALLA, C. M. A Classificaçáo Internacional de Funcionalidade, Incapacidade e Saúde da Organização Mundial da Saúde: Conceitos, Usos e Perspectivas. In: ALMIRALIAN, M. L. T. et. al. Conceituando Deficiência. In: MATHEUS, N. de M.; SCHLIEMANN, A. L. A construção do conceito de deficiência na área da saúde. Disponível em: http://www4.pucsp.br/pac/downloads/artigo_construcao_conceito.pdf. Acesso em: 12 nov. 2015. 
FÁVERO, E. A. G. Direitos das pessoas com deficiência: garantia de igualdade na diversidade. In: TSUTSUI, P. F. O novo conceito de pessoa com deficiência. Conteúdo Jurídico, Brasília-DF: 18 mar. 2014. Disponível em: <http://www.conteudojuridico.com. $\mathrm{br} /$ ?artigos\&ver $=2.47458 \&$ seo $=1>$. Acesso em: 15 nov. 2015.

FONSECA, R. T. M.. A ONU e o seu Conceito Revolucionário de Pessoa com Deficiência. Disponível em: http://www2.portoalegre.rs.gov.br/smacis/default. php?reg=4\&p_secao=96. Acesso em 12 nov. 2015 .

MAIA, M. Novo conceitode pessoa com deficiência e proibiçáo do retrocesso. Disponível em: http://webcache.googleusercontent.com/search?q=cache:-YWSeJ8O09sJ:www.agu. gov.br/page/download/index/id/17265873+\&cd=1\&hl=pt-BR\&ct=clnk\&gl=br. Acesso em 12 nov. 2015.

MENDES, G. F. Curso de Direito Constitucional. Saraiva: São Paulo, 2011.

PIOVESAN, F. Temas de Direitos Humanos. Saraiva: São Paulo, 2009. 
